\title{
Faset sendromu olan osteoporotik hastalarda pulse radyofrekans yönteminin etkinliğinin değerlendirilmesi
}

\author{
Evaluation of the effectiveness of pulsed radiofrequency method in osteoporotic \\ patients with facet syndrome
}

Kemal Paksoy

\section{Öz}

Amaç: Kronik omurga ağrıları olan osteoporozlu hastaların kliniğine lomber faset sendromunun eşlik etmesi sonucu yaşam kalitesi belirgin bozulmaktadır. Biz bu çalışmada lomber faset pulse radyofrekans yöntemi uygulaması ile faset kaynaklı ağrıları tedavi etmeyi ve hastaların ağrıları nedeniyle kullandıkları medikal tedaviyi azaltmayı amaçladık.

Gereç ve yöntem: Çalışmamıza osteoporoz nedeniyle takip edilen, nörolojik defisiti ve osteoporoza sekonder fraktürü olmayan hastalar dahil edildi. Hastaların en az 5 yıllık endokrinoloji, fiziksel tedavi veya ortopedi takipleri vardı. Bu hastalar osteoporoz temel tedavisinin yanında ön planda bel ağrısı olan ve uzun süreli ağrıya yönelik medikal tedavi alan hastalardı. Yaş ortalaması 74,5 olan 7'si erkek 11'i kadın toplam 18 hastaya pulse radyofrekans uygulaması yapıldı. Hastaların klinik bulgularının ve işlemin etkinliğinin değerlendirilmesi işlem öncesi, işlem sonrası 1. gün, 3. ay ve 6. ay Vizüel Analog Skalası (VAS) ve Modifiye Oswestry İndeksi (MOI) kullanılarak yapıldı.

Bulgular: İşlem sonrası 14 hastanın 1. ayda ağrılarında belirgin düzeyde azalma oldu. İşlem öncesi VAS skoru 8 ile 10 arası olan hastaların işlem sonrası 1. ay VAS skorunun 1-4 arası olduğu tespit edildi. İşlem öncesi MOI indeksine göre 38-48 puan arasında olan hastaların işlem sonrası 1. ayda MOi indeksi 8-18 arasındaydı. 3 hastada VAS skoru 7 ile 10 ve MOİ indeks puanı 38-47 arası olup işlem sonrası kısmi ağrının devam ettiği görüldü. Yalnızca bir hastanın ağrılarında işlem öncesi ve sonrası karşılaştırmada değişiklik olmadığı görüldü.

Sonuç: Lomber faset pulse radyofrekans uygulamasının osteoporoza bağlı lomber faset ağrılarında medikal tedavileri azaltarak hasta yaşam koşullarını düzeltebilecek etkin ve alternatif bir yöntemdir.

Anahtar kelimeler: Faset sendromu, pulse radyofrekans, osteoporoz.

Paksoy K. Faset sendromu olan osteoporotik hastalarda pulse radyofrekans yönteminin etkinliğinin değerlendirilmesi. Pam Tıp Derg 2021;14:346-352.

\begin{abstract}
Purpose: In the patients with osteoporosis, their life qualities get worse due to stubborn spinal pains. We performed a lumbar facet pulsed radiofrequency method application to treat these pains and decrease the medical treatment the patients used for pain.

Material and methods: The patients, who had the diagnosis of osteoporosis with no neurologic deficit and no fracture related to osteoporosis, were chosen. In order to evaluate the clinical findings of the patients and the activity of the procedure, they were evaluated with Visual Analogous Scale (VAS) and Modified Oswestry Index (MOI) on the 1st day, in the 3rd and 6th month before and after the procedure.

Result: The pains of the 14 patients prominently decreased in the 1st month after the procedure. It was detected that VAS score before the procedure was between 8-10, and VAS score was between 1-4 in the 1st months after the procedure. In these patients, who were between 38-48 points according to $\mathrm{MOI}$ index, in the 1st month after the procedure MOI index was between 8-18. VAS score was between 7-10 and MOI index point was between 38-47 in 3 patients, it was observed that a partial relaxation continued after the procedure.

Conclusion: Lumbar facet pulsed radiofrequency application can be a method that provides an alternative way for the pain, which can get ahead of the intensive medical treatment and improve the patient's life conditions without causing a financial burden like a medical treatment for lumbar pains related to osteoporosis.
\end{abstract}

Key words: Facet syndrome, pulsed radiofrequency, osteoporosis.

Paksoy K. Evaluation of the effectiveness of pulsed radiofrequency method in osteoporotic patients with facet syndrome. Pam Med J 2021;14:346-352. 


\section{Giriş}

Osteoporoz, en sık rastlanan iskelet sistemi hastalığı olup kemik kütlesinde azalma ve kemik dokusunun mikro yapısının bozulmasıyla karakterize bir hastalıktır. Buna bağı kemik kırılganlığında artma söz konusudur [1]. Yaşlanan toplumlarda önemli bir halk sağlığı sorunudur. Osteoporozda kas iskelet sistemine bağlı ağrılar ön plandayken özellikle hastalarda inatçı bel ağrılarına bağlı yaşam kalite değerleri bozulmaktadır [2]. Genel olarak uzun süren bu tip ağrılar aynı zamanda kişisel ve toplumsal ekonomi açısından önemli derecede mali yük oluşturmaktadır [3]. Bu tip hastalarda bel ağrılarının nedenlerinden bir tanesi de lomber faset ağrılarıdır. Bu kliniğe lomber faset sendromu (LFS) neden olur. Lomber faset sendromu; lomber bölgedeki faset eklemlerinin yaşlanmasına bağlı veya travma sebebiyle oluşan instabilite sendromudur [4]. Klinik olarak LFS'de radiküler yayılımı olmayan bel ağrısı mevcuttur. Ağrı ayakta durmakla, lomber ekstansiyonla, patolojik fasetin olduğu tarafa lateral fleksiyon ve rotasyon ile artar. Oturmakla ve lomber fleksiyonla azalır [5]. Tanısal olarak spesifik bir görüntüleme yöntemi yoktur. En iyi tanı yöntemi LFS düşünülen eklemin bloklanması ile ağrının azalmasıdır [6]. Lomber faset sendromunda instabilitenin ön planda olduğu durumlarda tedavi cerrahidir. LFS hastalıklarında instabilite ön planda olmadığı durumlarda temel yaklaşım şekli medikal tedavi ve fizik tedavi şeklindeki konservatif yaklaşımlardır. Ağrı sorununun çözülemediği durumlarda ise tedavi yöntemi perkutan invaziv girişimsel işlemlerdir [7]. Radyofrekans (RF) yöntemi kronik ağrı tedavisinde son yıllarda uygulanan nöroablasyon yaratarak ağrı iletimini durdurmak amacıyla kullanılmaktadır. Bu yöntemle oldukça başarıı sonuçlar alınmaktadır [8].

Çalışmamızdaki amacımız ağrı üzerinde etkinliği kanıtlanmış pulse radyofrekans yönteminin osteoporozlu hastalarda var olan faset sendromunun oluşturduğu bel ağrılarına ve klinik iyilik haline etkinliğini VAS ve MOI testleri ile değerlendirmekti.

\section{Gereç ve yöntem}

Bu çalışma Ocak-Eylül 2019 tarihleri arasında Rize Kaçkar Devlet Hastanesi'nde yürütüldü. Çalışmamız Rize Sağlık İ Müdürlüğü’nden etik onayı alınarak; etik, hukuki ve bilimsel kurallara uygun olarak yapıldı. Hastalardan ayrıntılı yazılı onamlar alındı.

\section{Kabul Kriterleri:}

1. Hastaların osteoporoz tanısı almış ve tedavilerinin devam ediyor olması

2. LFS ön tanılı hastalara lomber faset eklem blokajı uygulanıp ağrıda en az \%50 azalma olması

3. Hastaların nörolojik defisitlerinin olmaması

4. Bel ağrısına neden olabilecek infeksiyöz, inflamatuar, tümöral ve metabolik hastalıklarının olmaması

\section{Dışlama kriterleri:}

1. Lomber faset eklem blokajında $\% 50$ 'nin altında ağrıda azalma

2. Osteoporoza sekonder vertebra fraktürüne bağlı bel ağrısı olan hastalar

Çalışmaya dahil edilen hastalarımıza lomber faset sendromu nedeniyle PRF ile denervasyon uygulaması planlandı. Rutin olarak bütün hastaların kanama pıhtılaşma testlerine bakıldı. Ameliyathanede yapılacak radyofrekans uygulaması için hastalardan en az sekiz saatlik açlık istendi. Monitorizasyondan sonra hastalar; prone pozisyonda, yumuşak elastik yastıklar bası oluşturmaktan kaçınmak için abdomenin lateral kısımlarına koyuldu. C kollu skopi kullanılarak anterior-posterior (AP) ve lateral floroskopik görüntüler alındı. Uygulanacak lomber faset seviyeleri tespit edilerek işaretlemesi yapıldı. İşaretlenen seviyelere \%1'lik lidokain cilt-cilt altına lokal anestezi uygulandı. Daha sonra skopi eşliğinde radyofrekans için kullanılacak özel bir elektrot (22 G, 5 mm'lik aktif uçlu elektrot) ile işleme başlandı. Transvers prosese yaklaşınca foramenin süperior ve dorsaline doğru yönlendirildi. Elektrodun ucu, AP görüntülemede faset eklemin ortasına, lateral görüntülemede ise foramenin üst ve dorsal alanına yerleştirildi. Şekil 1'de PRF uygulamasının şematik-manyetik rezonans görüntüleme görüntüsü, Şekil 2'de ise şematik-floroskopik görüntüsü mevcuttur. Duyusal ve motor uyarı tamamlandıktan sonar işlem uygulanacak alana lokal anestezi uygulandı. 3-5 dakika beklendikten sonra $42^{\circ} \mathrm{C}$ ve 6 dakika pulse radyofrekans uygulandı. Bütün hastalara işlem sonunda $2 \mathrm{ml}$ volüm 
içinde Metilprednisolon ve Levobupivakain yapıldı. İşlem sonrası hastalar 6 saat süre ile serviste takip edilip birkaç gün istirahat önerileri ile taburcu edildi. Taburcu edilen hastaların radyofrekans tedavisi sonrası 1, 3 ve 6 . aylarda kontrolleri yapıldı. Çalışmaya dahil edilen hastaların yaş, cinsiyet, daha önce aldığı tedavi (ilaç tedavisi, fizik tedavi), tedavi öncesi Vizüel Analog Skalası (VAS) ve Modifiye Oswestry İndeksi (MOI) skorları, tedavi sonrası VAS ve MOİ skorları kaydedildi.

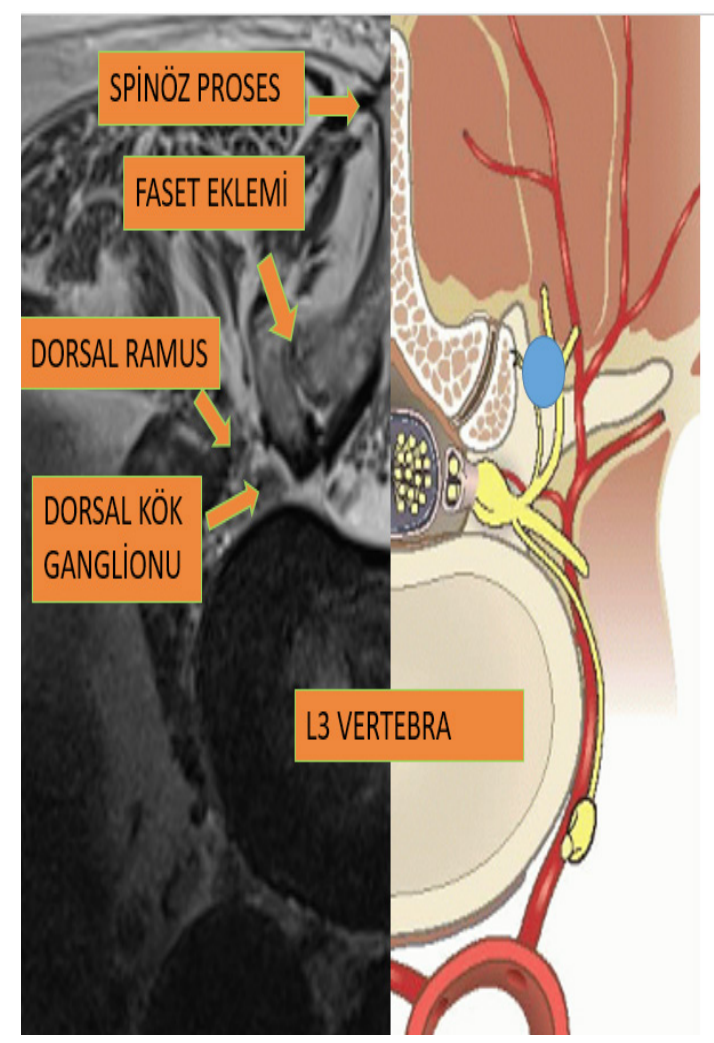

Şekil 1. Lomber faset sendromunda pulse rafyofrekansın uygulama yerinin şekilsel görüntüsü

Dorsal ramus üzerindeki hedef alanı göstermektedir

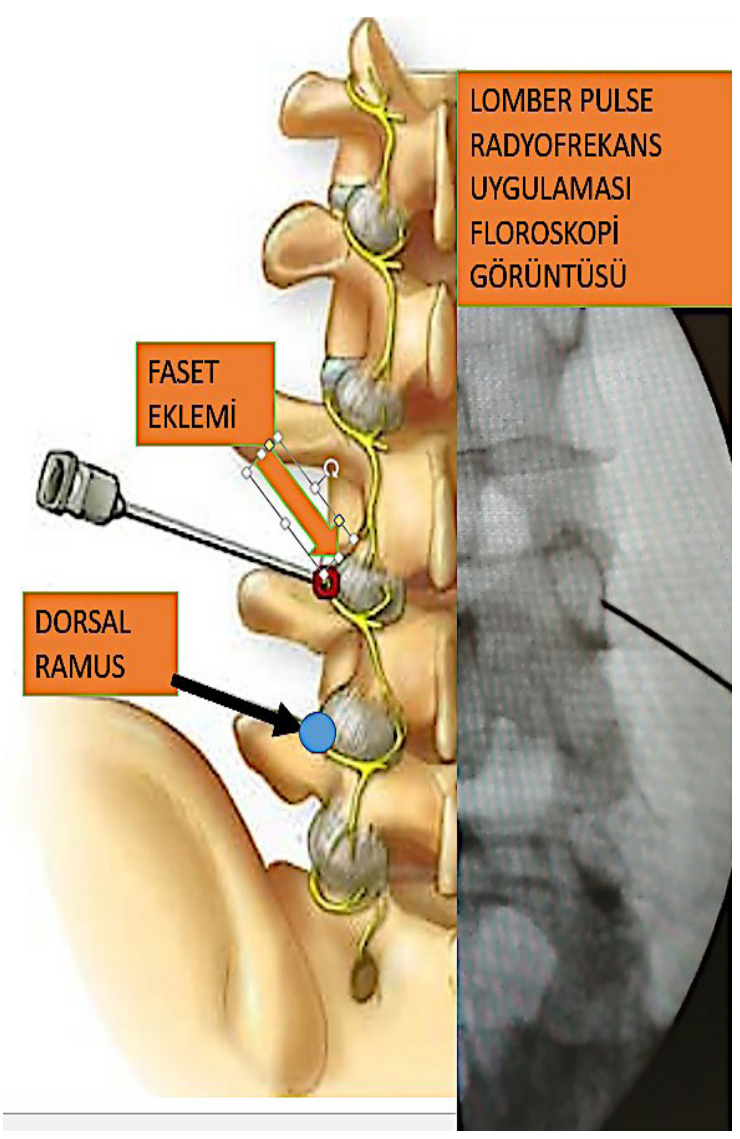

Şekil 2. Lomber pulse radyofrekans uygulamasının şematik ve floroskopik görüntüsünü

Dorsal ramus üzerindeki hedef alanı göstermektedir

\section{Bulgular}

İşlem sonrası 14 hastada 1. ayda ağrıları belirgin düzeyde azaldı. İşlem öncesi VAS skoru 8 ile 10 arası olan hastaların işlem sonrası VAS skoru 1. ayda 1-4 arası olduğu tespit edildi. $\mathrm{Bu}$ hastaların 3. ve 6. ayda VAS skorlarında anlamlı bir değişiklik olmadığı ve klinik iyilik halinin devam ettiği gözlemlendi. Bu hastalarda MOI indeksine göre 38-48 puan arasında olan hastaların işlem sonrası 1 ayda MOI indeksi 8-18 arası olduğu, 3. ve 6. aylarda MOI indeksi 5-11 arası olduğu tespit edildi. 3 hastada VAS skoru 7 ile 10 arası olup işlem sonrası 1. ayda VAS 5 ile 6 arasında olup 3. ve 6. aylarda kısmi rahatlamanın devam ettiği görüldü. Bu hastaların MOI indeks puanı 38-47 arası olup işlem sonrası 1. ayda MOİ 10-21 arasında, 3. ve 6. aylarda MOİ indeks puanı 8-15 arası tespit edildi. Yalnızca 1 hastada ağrılarında hiç 
değişiklik olmadı. İşlem öncesi ve işlem sonrası ardışık zamanlarda VAS skoru 9 olarak görüldü. Bu hastanın MOI indeks puanı işlem öncesi 42 olup işlem sonrası 1. ay 38,3 . ay 41 ve 6 . ay 41 puan olarak tespit edildi. Sadece 3. ay belirgin rahatlayan hastalardan bir tanesinin 6. ayda ağrısında işlem öncesine göre aynı olduğu görüldü. Bu veriler ışığı altında Friedman Testi ile istatistiksel olarak değerlendirilmesi

Tablo 1. VAS istatistiksel değerleri yapıldı. VAS ve MOI değerlerinde $p<0,05$ olup istatistiksel anlamlı olarak değişmiş olduğu görüldü (Tablo 1, 2). Aylar arasındaki VAS ve MOI değerleri Wilcoxon Signed Ranks Testi ile karşılaştııılarak değerlendirme yapıldı. VAS ve MOI değeri için anlamlılık $p<0,05$ olup işlem öncesi ile 1. ay, 3 . ay ve 6 . ay arasındaki farklılık anlamlıdır (Tablo 3, 4).

\begin{tabular}{lllllll}
\hline & N & Minimum & Maksimum & Mean & Std. Deviation & Test Statistics $^{\text {a }}$ \\
\hline İşlem Öncesi VAS & 18 & 7 & 10 & 42,11 & 3,179 & 18 \\
VAS 1.ay & 18 & 1 & 9 & 21,06 & 8,003 & 41,948 \\
VAS 3.ay & 18 & 1 & 9 & 16,67 & 8,758 & 3 \\
VAS 6.ay & 18 & 1 & 9 & 16,61 & 10,600 & 18 \\
Valid N (listwise) & 18 & & & & & \\
\hline
\end{tabular}

a. Friedman testi

Tablo 2. MOI istatistiksel değerleri

\begin{tabular}{lllllll}
\hline & N & Minimum & Maksimum & Mean & Std. Deviation & Test Statistics $^{a}$ \\
& & & & & & \\
\hline İşlem Öncesi MOI & 18 & 38 & 48 & 42,11 & 3,179 & 18 \\
MOi 1.ay & 18 & 8 & 38 & 21,06 & 8,003 & 41,948 \\
MOi 3.ay & 18 & 5 & 40 & 16,67 & 8,758 & 3 \\
MOi 6.ay & 18 & 4 & 41 & 16,61 & 10,600 & 18 \\
Valid N (listwise) & 18 & & & & & \\
\hline
\end{tabular}

a. Friedman testi

Tablo 3. VAS karşılaştırmalı istatistiksel değerleri

\begin{tabular}{lllllll}
\hline & $\begin{array}{l}\text { 1.ay VAS- } \\
\text { İşlem Öncesi } \\
\text { VAS }\end{array}$ & $\begin{array}{l}\text { 3.ay VAS- } \\
\text { Işlem Öncesi } \\
\text { VAS }\end{array}$ & $\begin{array}{l}\text { 6.ay VAS- } \\
\text { İşlem Öncesi } \\
\text { VAS }\end{array}$ & $\begin{array}{l}\text { 3.ay VAS- } \\
\text { 1.ay VAS }\end{array}$ & $\begin{array}{l}\text { 6.ay VAS- } \\
1 \text { 1.ay VAS }\end{array}$ & $\begin{array}{l}\text { 6.ay VAS - 3.ay } \\
\text { VAS }\end{array}$ \\
\hline Z & $-3,637 \mathrm{~b}$ & $-3,635 \mathrm{~b}$ & $-3,630 \mathrm{~b}$ & $-2,863 \mathrm{~b}$ & $-2,174 \mathrm{~b}$ &,$- 359 \mathrm{c}$ \\
Asymp.Sig. &, 000 &, 000 &, 000 &, 004 &, 030 &, 719 \\
(2tailed) & & & & & & \\
\hline
\end{tabular}
a. Wilcoxon signed ranks test
b. Based on positive ranks
c. Based on negative ranks 
Tablo 4. MOI karşılaştırmalı istatistiksel değerleri

\begin{tabular}{|c|c|c|c|c|c|c|}
\hline & $\begin{array}{l}\text { 1.ay MOI- } \\
\text { İşlem Öncesi } \\
\text { MOİ }\end{array}$ & $\begin{array}{l}\text { 3.ay MOI- } \\
\text { İşlem Öncesi } \\
\text { MOİ }\end{array}$ & $\begin{array}{l}\text { 6.ay MOI- } \\
\text { İşlem Öncesi } \\
\text { MOİ }\end{array}$ & $\begin{array}{l}\text { 3.ay MOİ - } \\
\text { 1.ay MOİ }\end{array}$ & $\begin{array}{l}\text { 6.ay MOİ - } \\
\text { 1.ay MOİ }\end{array}$ & $\begin{array}{l}\text { 6.ay MOİ - } \\
\text { 3.ay MOİ }\end{array}$ \\
\hline Z & $-3,724 b$ & $-3,726 b$ & $-3,725 b$ & $-3,290 b$ & $-3,271 b$ &,$- 539 b$ \\
\hline $\begin{array}{l}\text { Asymp. Sig. } \\
\text { (2-tailed) }\end{array}$ &, 000 &, 000 &, 000 &, 001 & ,001 &, 590 \\
\hline
\end{tabular}

a. Wilcoxon signed ranks test

b. Based on positive ranks

\section{Tartışma}

Bel ağrısı, insanların yaklaşık \%70'inin yaşamları boyunca yaşadıkları en yaygın hastalıklardan biridir. Bununla birlikte oluşan iş gücü kaybı ve maddi yük nedeni ile son zamanlarda daha çok ilgi çekmeye başlamıştır. $\mathrm{Bu}$ nedenle son yıllarda risk faktörlerinin belirlenmesi, kronik hastalıkların özelliklerinin tanınması, tanı ve tedavideki tıbbi gelişmeler önem kazanmıştır [9]. Osteoporoz, düşük kemik mineral yoğunluğu (KMY) ile oluşan sistematik bir hastalık olup kırık riski ile karakterizedir. Kronik bir hastalıktır. Osteoporoz tedavisinde amaç kemik gücünü arttırarak kırıkları önlemek böylece yeni kırık insidansını azaltarak oluşabilecek mortalite ve morbiditeyi azaltmaktır [10]. Günümüzde gelişen teknoloji ve sağlık hizmetleriyle bireylerin yaşam süreleri giderek uzamaktadır. Toplumun yaş ortalamasının artmasına bağlı olarak osteoporoz tanısı ile daha fazla sayıda bireyler osteoporoz tedavisi almaktadır. Bu durumda osteoporozun primer tedavisinin maliyetini yükseltmektedir [11]. $\mathrm{Bu}$ dejeneratif süreç içerisinde vertebralarda osteoporozdan etkilenmektedir. Klinik olarak kırıksız bel ağrıları ve faset sendromları görülme riski artmaktadır [12]. Bel ağrılarının \%85'inin hastalarda etiyolojisi belli değildir. Bel ağrısı tedavisinde multidisipliner yaklaşım önemlidir. Tedavide genellikle sırası ile yapılacak yaklaşımlar medikal tedavi, fizik tedavi, perkütan invaziv girişimler ve cerrahi olarak sınıflandırılabilir [13]. Kronik bel ağrılarının \%15'i faset eklem kaynaklıdır. Faset eklem kaynaklı ağrıların tedavi yönetiminde ise öncelikli olarak yatak istirahati ve analjezikler kullanıımalı devam eden inatçı ağrılarda fizik tedavi programları uygulanmalıdır. Semptomatik iyileşme görülmeyen hastalarda ise invaziv teknikler (radyofrekans denervasyon, kriyo- denervasyon, lokal uygulamalar vb.) uygulanır [14]. Lomber faset eklem sendromunda temel yöntem medial dalın blokajıdır [15]. Klinik olarak LFS düşünülen hastaların tanısını desteklemek için hastaya bloklama yapılır. Bloktan sonra hastanın ağrısındaki yarıdan fazla azalma tanıyı doğrulamaktadır. Bu aşamadan sonra radyofrekans termokoagulasyon yöntemi uygulanır. 1971 yılında Rees [16] ilk kez cerrahi yöntemle faset eklemindeki artiküler sinirleri keserek faset rizotomiyi gerçekleştirmiştir. 1973 yılında Shealy [17] faset eklem denervasyonunu perkütan radyofrekans termokoagülasyon yöntemi ile uygulamıştır. Radyofrekans termokoagulasyon kronik ağrılarda selektif sinir harabiyeti oluşturarak ağrı çözümünde etkili olur. İki farklı tipi vardır. Konvansiyonel RF uygulamasında ısı ile doku hasarı oluşturulurken, PRF ise klinik olarak nondestrüktif bir uygulamadır. Sluijter ve Cosman tarafından PRF geliştirilmiştir. PRF uygulaması düşük ısı ile ağrı kontrolü sağlanmaktadır [18]. PRF'ın refraktör ağrılı sendromlarda veya konservatif tedavinin tolere edilemediği durumlarda alternatif bir tedavi olarak güvenle kullanılabilir [19]. Chao ve ark. [20] yapmış olduğu çalışmada lumbar ve servikal ağrılarda pulse RF uygulamasının orta süreli ağrılarda, Abejon ve ark. [21] lumbar disk hernili ve spinal stenozlu vakalarda faydalı olduğunu göstermişlerdir. Hussain ve ark. [22] ise başarısız bel cerrahisi geçiren hastalarda ağrı tedavisi için tercih edilebilir bir yöntem olarak pulse RF'। göstermişlerdir. Gofeld ve ark. [23] yapmış olduğu faset eklemlerin RF denervasyonunun hastalarda ağrıda rahatlama sağladığı sonucuna varmışlardır. Mikeladze ve ark. [24] yaptığı çalışmada kronik faset eklem ağrısı olan hastaların ağrısının rahatlamasını sağladığı görülmüştür. Bizimde yaptığımız çalışmada literatüre benzerlik göstermiştir. Osteoporoz hastasında bel ağrısına neden 
olabilecek durum vertebra kırığıdır. Ancak osteoporoza bağlı kırıkların çoğu başlangıçta minör kırıklardır. Minör kırıklar vertebralarda şekil bozukluğu yapar. Osteoporoza eşlik eden dejeneratif süreç faset yapılarını bozarak ağrı oluşturur [25]. Çalışmamızda hastaların görüntülemelerinde akut ağrı oluşturabilecek vertebra kırığı tespit edilmedi. Faset sendromundan dolayı bel ağrısı olan osteoporoz hastalara pulse RF işlemi uygulandı. Literatürü destekler şekilde PRF uygulamasının etkinliği istatistiksel olarak anlamlı bulunmuştur. Hasta seçiminin uygulamanın başarısında etkili olduğu ve bu nedenle altta yatacak başka bir neden olup olmadığı araştırılmalıdır. Beklentinin hastaya doğru şekilde aktarılması da önemli diğer bir faktördür.

Sonuç olarak, osteoporoz toplumda sık görülen ve inatçı ağrılar ile seyri olan bir hastalıktır. Bu süreçte ağrılara yönelik birçok tedavi yapılmaktadır. En büyük payı medikal tedavi tutmaktadır. Medikal tedavin yoğun ilaç kullanmasının yanında hastalara maddi yük oluşturmaktadır. Bu bağlamda lomber faset radyofrekans uygulaması osteoporoza bağlı lomber ağrılarda medikal tedavi gibi mali bir yük getirmeden yoğun medikal tedavisinin önüne geçebilecek ve hasta yaşam koşullarını düzeltebilecek ağrıya yönelik alternatif bir yöntem olabilir.

Çıkar ilişkisi: Yazarlar çıkar ilişkisi olmadığını beyan eder.

\section{Kaynaklar}

1. Anonymous. Consensus development conference: diagnosis, prophylaxis, and treatment of osteoporosis. Am J Med 1993;94:646-650. https://doi. org/10.1016/0002-9343(93)90218-e

2. Fonseca $H$, Moreira Gonçalves $D$, Coriolano HJA, Duarte JA. Bone quality: the determinants of bone strength and fragility. Sports Med 2014;44:37-53. https://doi.org/10.1007/s40279-013-0100-7

3. Breivik H, Collett B, Ventafridda V, Cohen R, Gallacher $D$. Survey of chronic pain in Europe: prevalence, impact on daily life, and treatment. Eur J Pain 2006;10:287333. https://doi.org/10.1016/j.ejpain.2005.06.009

4. Schwarzer AC, Aprill CN, Derby R, Fortin J, Kine G, Bogduk $N$. The relative contributions of the disc and zygapophyseal joint in chronic low back pain. Spine 1994;19:801-806. https://doi.org/10.1097/00007632199404000-00013
5. Jackson RP, Jacobs RR, Montesano PX. 1988 Volvo award in clinical sciences. Facet joint injection in low-back pain: a prospective statistical study. Spine 1988;13:966-971. https://doi.org/10.1097/00007632198809000-00002

6. Falco FJE, Manchikanti L, Datta S, et al. An update of the systematic assessment of the diagnostic accuracy of lumbar facet joint nerve blocks. Pain Physician 2012;15:869-907.

7. Roelofs PDDM, Deyo RA, Koes BW, Scholten RJPM, van Tulder MW. Nonsteroidal anti-inflammatory drugs for low back pain: an updated Cochrane review. Spine 2008;33:1766-1774. https://doi.org/10.1097/ BRS.0b013e31817e69d3

8. Sluijter ME. Radiofrequency, part 1: the lumbosacral region. FlivoPress. Switzerland 2001:50-51.

9. Barrero LH, Hsu YH, Terwedow H, et al. Prevalence and physical determinants of low back pain in a rural Chinese population. Spine 2006;31:2728-2734.

10. Coughlan $T$, Dockery F. Osteoporosis and fracture risk in older people. Clin Med 2014;14:187-191. https://doi. org/10.7861/clinmedicine.14-2-187

11. Das S, Crockett JC. Osteoporosis - a current view of pharmacological prevention and treatment. Drug Des Devel Ther 2013;7:435-448. https://doi.org/10.2147/ DDDT.S31504

12. Cosman F, de Beur SJ, LeBoff MS, et al. National Osteoporosis Foundation. Clinician's guide to prevention and treatment of osteoporosis. Osteoporos Int 2014;25:2359-2381. https://doi.org/10.1007/ s00198-014-2794-2

13. Van Tulder MW, Touray T, Furlan AD, Solway S, Bouter LM. Cochrane Back Review Group. Muscle relaxants for nonspecific low back pain: a systematic review within the framework of the cochrane collaboration. Spine 2003;28:1978-1992. https://doi.org/10.1097/01. BRS.0000090503.38830.AD

14. Bogduk N. A narrative review of intra-articular corticosteroid injections for low back pain. Pain Med 2005;6:287-296. https://doi.org/10.1111/j.15264637.2005.00048.x

15. Cohen SP, Raja SN. Pathogenesis, diagnosis, and treatment of lumbar zygapophysial (facet) joint pain. Anesthesiology 2007;106:591-614. https://doi. org/10.1097/00000542-200703000-00024

16. Rees S. Unilateral lumbar facet joint hypertrophy causing nerve root irritation. Ann R Coll Surg Engl 1989;71:144-145.

17. Shealy CN. Percutaneous radiofrequency denervation of spinal facets. Treatment for chronic back pain and sciatica. J Neurosurg 1975;43:448-451. https://doi. org/10.3171/jns.1975.43.4.0448 
18. Slappendel R, Crul BJ, Braak GJ, et al. The efficacy of radiofrequency lesioning of the cervical spinal dorsal root ganglionin a double blinded randomized study: no difference between 40 degrees $\mathrm{C}$ and 67 degrees C treatments. Pain 1997;73:159-163. https://doi. org/10.1016/s0304-3959(97)00094-8

19. Cohen SP, Stojanovic MP, Crooks M, et al. Lumbar zygapophysial (facet) joint radiofrequency denervation success as a function of pain relief during diagnostic medial branch blocks: a multicenter analysis. Spine J 2008;8:498-504. https://doi.org/10.1016/j. spinee.2007.04.022

20. Chao SC, Lee HT, Kao TH, et al. Percutaneous pulsed radiofrequency in the treatment of cervical and lumbar radicular pain. Surg Neurol 2008;70:59-65. https://doi. org/10.1016/j.surneu.2007.05.046

21. Abejón D, Garcia del Valle S, Fuentes ML, Gómez Arnau JI, Reig E, van Zundert J. Pulsed radiofrequency in lumbar radicular pain: clinical effects in various etiological groups. Pain Pract 2007;7:21-26. https://doi. org/10.1111/j.1533-2500.2007.00105.x

22. Hussain AM, Afshan G. Use of pulsed radiofrequency in failed back surgery syndrome. J Coll Physicians Surg Pak 2007;17:353-355.

23. Gofeld M, Jitendra J, Faclier G. Radiofrequency denervation of the lumbar zygapophysial joints: 10-year prospective clinical audit. Pain Physician 2007;10:291300.

24. Mikeladze G, Espinal R, Finnegan R, Routon J, Martin D. Pulsed radiofrequency application in treatment of chronic zygapophyseal joint pain. Spine J 2003;3:360362. https://doi.org/10.1016/s1529-9430(03)00065-2

25. Mantyh PW. The neurobiology of skeletal pain. Eur J Neurosci 2014;39:508-519. https://doi.org/10.1111/ ejn.12462

Etik kurul onayı: Rize Sağlık il Müdürlüğü'nden 30/06/2020 tarih ve 64247179799 sayı numarası ile onay alınmıştır. 